etc has gained a lot of interest. By September 2016 we will have experiences to share.

Conclusions The project gives us ne possibilities to increase awareness and involve new groups in community safety.

\section{SUPPORTING A JOINT JOURNEY TOWARDS ZERO: CASE FINNISH ZERO ACCIDENT FORUM}

Tommi Alanko, Riikka Ruotsala, Jaana Luomanen. Finnish Institute of Occupational Health, Finland

\subsection{6/injuryprev-2016-042156.89}

Background Developing proactive safety culture in today's dynamic and turbulent business environment calls for inspiring approaches and effective safety practices. The Zero Accident Vision (ZAV) is based on the belief that all accidents are preventable. It should not be understood as a target or a numeric goal but more widely as a journey where genuine commitment plays an important role. In Finland the Zero Accident Forum was founded in 2003 to support workplaces in promoting safety and health. In November 2015 it had 337 member organisations.

Description of the problem In 2015 the Forum started to develop its activity to the next level to better respond to the members' needs. A new web portal is being developed to support more effective communication and learning. A question was raised whether the designed portal and its contents are what the members really wanted. To tackle this problem an agile development method was chosen as a method to get the member workplaces' needs and ideas integrated in the new portal.

Results To have a reliable estimation of the effects of the new portal we will measure appropriate variables; the occupational accident frequency and the workplaces' satisfaction with the service. During last review 2008-2012, the member workplace accident frequency had decreased by $46 \%$ while at national level the decreased was $7 \%$. The updated review will show how the members have succeeded in accident prevention. Also a usability and satisfaction survey will be conducted in spring 2016. The results will show how well the customer needs were taken into account.

Conclusions The new portal will support the Forum's main function: networking between workplaces and learning together. In the presentation we will illustrate the benefits the new web portal brings to communication, learning and benchmarking within the network. By presenting the results we want to inspire other stakeholders to take an initiative and steps forward in building and developing learning networks in the field of OHS.

\section{ASSOCIATION OF POST-TRAUMATIC STRESS DISORDER WITH WORK PERFORMANCE AMONGST EMERGENCY MEDICAL SERVICE PERSONNEL, KARACHI, PAKISTAN}

'Salima Kerai, 'Muhammad Islam, 'Uzma Khan, 'Nargis Asad, ${ }^{1}$ Junaid Razzak, ${ }^{1}$ Omrana Pasha. 'Aga Khan University, Pakistan; ${ }^{2}$ Johns Hopkins University, U.S.A

\subsection{6/injuryprev-2016-042156.90}

Background Emergency medical service (EMS) personnel are exposed to various stressors in their day to day functioning. They are exposed to various kinds of stressors which includes but not limited to handling dead children, medical emergencies, severe injuries, acts of violence, organisational problems etc. Their daily exposure to diverse critical and traumatic incidents can lead to stress reactions like Post-Traumatic Stress Disorder (PTSD). Consequences of PTSD in terms of work loss can be catastrophic because of its compound effect on families, which affect them economically, psychologicaly as well as socialy. Therefore, it is critical to assess the association between PTSD and Work performance in Emergency Medical Service (EMS) if exist any.

Methods This prospective observational study was carried out at AMAN EMS in Karachi, Pakistan. EMS personnel were screened for potential PTSD using impact of event scale-revised (IES-R). Work performance was assessed on basis of five variables; number of late arrivals to work, number of days absent, number of days sick, adherence to protocol and patient satisfaction survey over the period of 3 months. In order to model outcomes like number of late arrivals to work, days absent and days late; negative binomial regression was used. Whereas logistic regression was applied for adherence to protocol and linear for patient satisfaction scores

Results Out of 536 EMS personnel, 525 were found to be eligible, of them 518 consented. However data on 507 were included because 7 left the job during study period. The mean scores of PTSD was found to be $24.0 \pm 12.2$. However, weak and insignificant association was found between PTSD and work performance measures: number of late arrivals $\left(\mathrm{RR}_{\mathrm{adj}} 0.99 ; 95 \% \mathrm{CI}\right.$ : 0.98-1.00), days absent $\left(\mathrm{RR}_{\text {adj }} 0.98\right.$; 95\% CI: 0.96-0.99), days sick $\left(\mathrm{Rr}_{\text {adj }} 0.99 ; 95 \% \mathrm{CI}: 0.98\right.$ to 1.00$)$, adherence to protocol $\left(\mathrm{OR}_{\mathrm{adj}}\right.$ 1.01: $95 \% \mathrm{CI}: 0.99$ to 1.04$)$ and patient satisfaction (0.001\% score; $95 \% \mathrm{CI}:-0.03 \%$ to $0.03 \%)$.

Conclusion Higher score of PTSD were found among EMS personnel signifying their exposure to range of stressful incidents from handling violence to trauma and other medical emergencies. No association was found between PTSD and Work performance in the selected EMS population in Karachi Pakistan. Further studies are needed to explore the phenomenon of resiliency in this population.

\section{NATIONAL ACTION PLAN ON WORKERS' HEALTH IN THE RUSSIAN FEDERATION}

Igor Bukhtiyarov, Evgeny Shigan, Nina Rubtsova. FSBSI "Research Institute of Occupational Health", Moscow, Russia

\subsection{6/injuryprev-2016-042156.91}

Background Resolution WHA 60.26 “Workers' Health: Global Plan of Action" urges countries to develop national action plans on workers' health according to the WHO global plan of action on workers' health 2008-2017.

Description of the problem The Russian Federation (RF) has developed strategic and operational plans for workers' health at the federal and sub-national level. Such plan should include: national profiles; priorities for action; objectives and targets; actions; mechanisms for implementation; human and financial resources; monitoring, evaluation and updating; reporting and accountability.

Results The action plan of occupational health is developed in accordance to policy of WHO collaborating centres for occupational health network The purpose of activity is to review the lessons learned from the previous plans and strategies on workers' health in RF, to develop a national profile of the situation on workers' health and to set up a planning process for updating the national action plan on workers' health in collaboration with WHO and other countries. FSBSI "Research Institute of 